\title{
Restoration of Lung Pressure-Volume Characteristics with Various Phospholipids
}

\author{
MACHIKO IKEGAMI, JAMES SILVERMAN, AND FORREST H. ADAMS
}

Division of Cardiology, Department of Pediatrics, University of California, Los Angeles, California USA

\begin{abstract}
Summary
The surfactant depleted adult rat lung model previously reported by us was used to determine the ability of certain phospholipids (PL), either singly or in combination, to restore the lung pressurevolume (PV) characteristics to normal. Seventy-one adult rats were used for this study. Before depletion of surfactant, a PV curve was obtained and the mean percent total lung capacity (\% TLC) at $5 \mathrm{~cm} \mathrm{H}_{2} \mathrm{O}$ on the deflation limb was 53.8. Maximal removal of surfactant was done by repeated lung washings, and a second PV curve was obtained (mean \% TLC was 9.2). Various PL suspensions were prepared by sonication of dipalmitoyl lecithin and another $P L$ in saline at a molar ratio of 9:1. The final concentration was $5 \mathrm{mg} \mathrm{DPL} / \mathrm{ml}$. Each suspension was instilled directly into the trachea and the lung was ventilated for $5 \mathrm{~min}$ at a rate of $40 / \mathrm{min}$, a volume of $7 \mathrm{ml}$, PEEP of $5 \mathrm{~cm} \mathrm{H} \mathrm{H}_{2} \mathrm{O}$, and an inspiration to total cycle ratio of 0.4. $A$ third $P V$ curve was then done. For all PV curves, the percent of original TLC at $5 \mathrm{~cm} \mathrm{H}_{2} \mathrm{O}$ was calculated. The $\%$ TLC at $5 \mathrm{~cm} \mathrm{H}_{2} \mathrm{O}$ after treatment with phospholipid suspensions, showed: DPL/unsaturated phosphatidyl glycerol (u-PG), 37.2; DPL/unsaturated phosphatidyl inositol (uPI), 28.3; DPL, 25.8; DPL/unsaturated phosphatidyl serine (uPS), 25.7; DPL/unsaturated lecithin (u-Lecithin), 24.1; DPL/dipalmitoyl phosphatidyl glycerol (DPPG), 7.7; and an analog of DPL from the University of Rhode Island (URI analog), 20.1. Although six of the seven suspensions possessed varying ability to restore the PV characteristics toward normal, none was as effective as natural surfactant which gave a mean of $\mathbf{4 6 . 8}$.
\end{abstract}

\section{Speculation}

Of the seven phospholipid mixtures, DPL/u-PG produced the most improvement in lung stability. Furthermore, surface tension measurements of DPL/u-PG showed normal surface activity. This suggests that DPL in combination with u-PG might afford a basis for development of a synthetic surfactant for treatment of respiratory distress syndrome (RDS).

Inasmuch as the development of RDS is probably due to deficiency of surfactant, one form of treatment might be the administration of a natural or synthetic surfactant into the airways. In a previous study (12), we compared the effectiveness of nebulization vs. direct tracheal instillation of natural or synthetic surfactant, in restoring the PV characteristics of surfactant-depleted rat lungs. The PV characteristics of the surfactant depleted rat lungs were similar to those in the lungs of infants dying of RDS (8). We found that only direct tracheal instillation of natural surfactant restored the PV characteristics to normal.

Recently, we have demonstrated (2) that tracheal instillation of natural surfactant into the premature lamb protects the lungs from developing many features characteristic of RDS. Several clinical and experimental studies have utilized a synthetic or natural surfactant $(3,5,22)$. Recent evidence would suggest that a number of phospholipids are important for lung stability $(7,9,10,14,20)$. Ivey et al. (13) have demonstrated clinical improvement in RDS by nebulization of a sonicated mixture of DPL and DPPG.
This study was designed to evaluate the efficacy of well-sonicated, 9:1 mixtures of DPL with various other phospholipids (i.e.. DPPG, u-PI, u-PS, u-PG, u-Lecithin), DPL alone, URI DPL analog alone, and natural surfactant in restoring the PV characteristics of adult rat lungs from which surfactant was removed by saline washings.

\section{MATERIALS AND METHODS}

Seventy-one adult rats weighing $300-450 \mathrm{~g}$ were used. After injecting $60 \mathrm{mg}$ sodium barbital into the peritoneal cavity, each rat was killed by transecting the abdominal aorta and allowing exsanguination to occur. The heart and lungs were then removed carefully en bloc.

The same methods were used as in our previous study (12) to obtain a PV curve except that the degassed lungs were placed in a saline water bath at $37^{\circ} \mathrm{C}$. The lungs were inflated gradually with air to $30 \mathrm{~cm} \mathrm{H}_{2} \mathrm{O}$ and then deflated in a similar manner. The volume reached at $30 \mathrm{~cm} \mathrm{H}_{2} \mathrm{O}$ was assumed to be the TLC. On the deflation limb of each PV curve, the volume at a pressure of $5 \mathrm{~cm} \mathrm{H}_{2} \mathrm{O}$ was expressed as a percent of TLC. PV measurements were made three times on each lung: initially; after removal of surfactant; and after treatment with various synthetic surfactants.

As described previously (12), surfactant was removed by washing the lung 20 times. A total volume of $200 \mathrm{ml}$ saline was used to insure maximal removal of surfactant. Lungs with volumes over $13 \%$ of total lung capacity at $5 \mathrm{~cm} \mathrm{H}_{2} \mathrm{O}$ on the deflation limb after washing were excluded from further analysis, because it was assumed that sufficient surfactant had not been removed.

\section{PREPARATION OF SYNTHETIC SURFACTANT}

Each synthetic surfactant was prepared by suspending DPL and another phospholipid in a molar ratio of 9:1 in saline so that the concentration of the solution was $10 \mathrm{mg} \mathrm{DPL} / \mathrm{ml}$. Each solution was sonicated in a water bath at $0^{\circ} \mathrm{C}$ using a Bronson Sonifier at $10 \mathrm{~mA}$ until the suspension appeared opalescent (approximately $5 \mathrm{~min}$ ). Approximately $15 \%$ of the phospholipid solution was lost during the sonication process due to the clinging of small droplets of the solution to the sonication probe. Each suspension was then diluted with saline to a concentration of $5 \mathrm{mg} \mathrm{DPL} / \mathrm{ml}$.

The individual phospholipids were obtained from the following sources: dipalmitoyl-DL- $\alpha$-phosphatidyl choline, unsaturated L- $\alpha$ phosphatidyl-DL-glycerol, unsaturated L- $\alpha$-phosphatidyl-inositol, and unsaturated $L-\alpha$-phosphatidyl-L-serine, were from the Sigma Chemical Company; unsaturated lecithin was extracted from rat liver and separated using thin layer chromotography; DPL/DPPG (9/1) was supplied by Dr. Stephen Roth of Johns Hopkins University; and URI analog was supplied by Dr. Joseph G. Turcotte of the University of Rhode Island. As shown in Figure 1, URI analog was a dipalmityl ether rather than a dipalmitoyl ester, and had a propylene phosphono polar head rather than an ethylene oxy phosphate polar head, and had an absolute configuration opposite that of DPL. All phospholipids were used without further purification.

Because Ivey et al. (13) used a phospholipid mixture of DPL/ DPPG sonicated at $15^{\circ} \mathrm{C}$, limited studies were done by us soni- 
cating three mixtures at $15^{\circ} \mathrm{C}$ as well as at $0^{\circ} \mathrm{C}$. They were DPL $(n=5), \mathrm{DPL} / \mathrm{u}-\mathrm{PG}(n=5)$, and DPL/DPPG $(n=7)$.

\section{PREPARATION OF NATURAL SURFACTANT}

The excised lungs of five newborn lambs (2-days old) were perfused free of blood with cold $0.9 \%$ saline. The lungs were cannulated with a tracheal tube and washed with cold saline. The turbid lung washings were centrifuged at $200 \mathrm{~g}$ at $20^{\circ} \mathrm{C}$ for $7 \mathrm{~min}$ to remove cell debris. The supernatant was further centrifuged at $1000 \mathrm{~g}$ at $2^{\circ} \mathrm{C}$ for $1 \mathrm{hr}$. The suspensions were pooled and again centrifuged at $1000 \mathrm{~g}$ at $2^{\circ} \mathrm{C}$ for $1^{\circ} \mathrm{hr}$. The pellet obtained was suspended in an equal volume of saline and resedimented at 200 $g$ at $2^{\circ} \mathrm{C}$ for $10 \mathrm{~min}$ to remove cell debris. This procedure was repeated until no yellow cellular layer was visible at the bottom. The resultant white layer was referred to as natural surfactant. The nonsonicated natural surfactant was then diluted to a phospholipid concentration of $5 \mathrm{mg} / \mathrm{ml}$. The chemical composition of the natural surfactant used is shown in Table 1.

\section{TREATMENT OF LUNGS}

Fourteen groups of animals were studied; in each group, a different preparation was instilled into the lungs. Initially, $5 \mathrm{ml}$ of the respective suspension was drawn into a syringe. The material was then warmed in the syringe at $45^{\circ} \mathrm{C}$ for $5 \mathrm{~min}$, and the entire $5 \mathrm{ml}$ of the substance was injected through a cannula into the lungs being careful to distribute the suspension evenly throughout each lobe. Then $3 \mathrm{ml}$ was slowly withdrawn, leaving a total of 2 $\mathrm{ml}$ of the suspension in the lungs. The cannula and lungs were then connected to a Harvard small animal respirator and ventilated for $5 \mathrm{~min}$ to further disseminate the infused material to all regions of the lungs. The ventilation rate was $40 / \mathrm{min}$, the PEEP was $5 \mathrm{~cm} \mathrm{H} \mathrm{H}_{2} \mathrm{O}$, and the volume was $7 \mathrm{ml}$ with an inspiration to a total cycle ratio of 0.4 .

University of Rhode Island DPL Analog

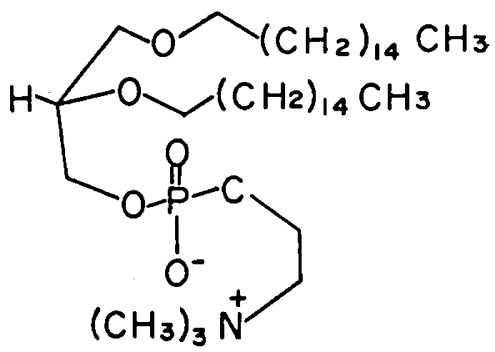

Fig. 1. Structure of the University of Rhode Island DPL Analog.

\section{SURFACE-TENSION MEASUREMENTS}

Measurements of the surface tension properties of each mixture was accomplished by two methods: the modified Wilhemy balance (6); and the dynamic alveolar model $(1,16)$ (Acoma Medical Industrial Company, Japan), which records the PV relationships of a micro-bubble oscillating 16 times/min from $1000 \mu$ to $600 \mu$ in diameter. The surface tension at $1000 \mu(\gamma \max )$ and $600 \mu(\gamma$ min) diameters was calculated from the pressure bubble diameter using the Laplace formula. The stability indices (SI) were then calculated according to the formula (4):

$$
\begin{gathered}
\mathrm{SI}=\frac{2(\gamma \max -\gamma \min )}{\gamma \max +\gamma \min } \\
\text { RESULTS }
\end{gathered}
$$

\section{RESULTS}

The \% TLC of the excised rat lungs at $5 \mathrm{~cm} \mathrm{H}_{2} \mathrm{O}$ before and after instillation of each suspension of surface active material is shown in Figure 2. The number of animals used in each group is also shown. The mean initial value for $\%$ TLC at $5 \mathrm{~cm} \mathrm{H}_{2} \mathrm{O}$ was $53.8 \pm 4.6$ and after washing $9.2 \pm 2.1$, which is representative of all the groups studied. The ability of each suspension to restore the PV characteristics toward normal is arranged in decreasing order. The mean \% TLCs at $5 \mathrm{~cm} \mathrm{H}_{2} \mathrm{O}$ were as follows: natural surfactant, 46.8; DPL/u-PG, 37.2; DPL/u-PI, 28.3; DPL, 25.8; DPL/u-PS, 25.7; DPL/u-Lecithin, 24.1; DPL/DPPG, 7.7; and URI analog 20.1. Although seven of the eight mixtures possessed varying ability to restore the PV characteristics towards normal, none was as effective as natural surfactant. All of the other mixtures were significantly less effective (i.e., $P<0.05$ ) when compared with natural surfactant. Of the seven synthetic phospholipid mixtures, DPL/u-PG produced the most improvement in lung stability and was significantly more effective than the remainder $(P<0.05)$.

As shown in Figure 3, DPL/u-PG and DPL sonicated at $15^{\circ} \mathrm{C}$ was less effective at restoring TLC at $5 \mathrm{~cm} \mathrm{H}_{2} \mathrm{O}$ toward pretreatment values than was DPL/u-PG or DPL sonication at $0^{\circ} \mathrm{C}$. Whereas sonicating DPL/DPPG at $15^{\circ} \mathrm{C}$ seemed to improve or increase significantly (i.e., $P<0.05$ ) its surface activity in comparison with sonication at $0^{\circ} \mathrm{C}$.

Table 1. Phospholipid composition of natural surfactant

\begin{tabular}{lc}
\hline & $\mathrm{mg} / \mathrm{ml}$ \\
\hline Total phospholipid & 5.0 \\
Lecithin & 4.1 \\
Saturated lecithin & 2.8 \\
Phosphatidyl ethanolamine & 0.25 \\
Sphingomyelin & 0.09 \\
Phosphatidyl glycerol & 0.18 \\
Phosphatidyl serine & 0.02 \\
Phosphatidyl inositol & 0.02 \\
\hline
\end{tabular}

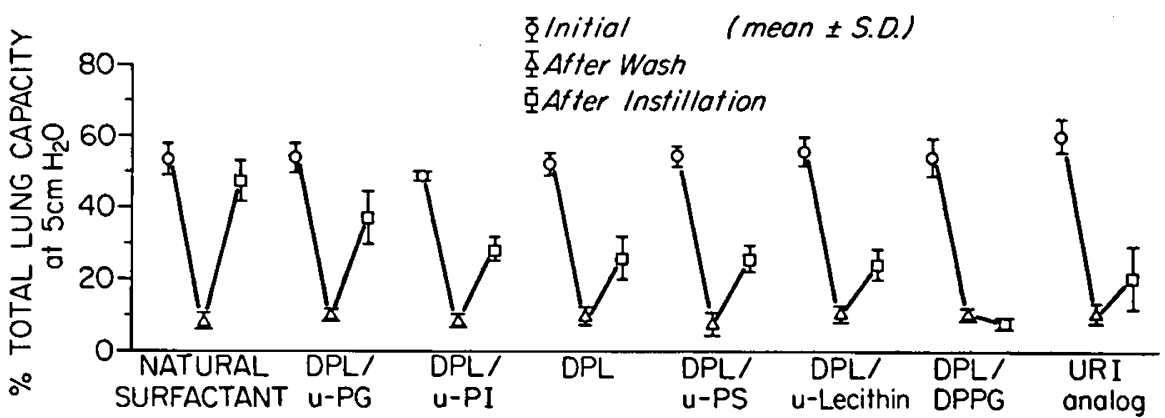

Fig. 2. A comparison of the percent of total lung capacity at $5 \mathrm{~cm} \mathrm{H}_{2} \mathrm{O}$ for control lungs, lungs washed with $200 \mathrm{ml}$ saline, and washed lungs that were treated with natural surfactant and phospholipid mixtures sonicated at $0^{\circ} \mathrm{C}$. DPL is dipalmitoyl lecithin, $\mathrm{u}-\mathrm{PG}$ is unsaturated phosphatidyl glycerol; u-PI is unsaturated P Inositol; u-PS is unsaturated P Serine; DPPG is dipalmitoyl phosphatidyl glycerol; URI is University of Rhode Island. In each case, $n=5$ with the exception of URI analog, $n=4$. 
Results of surface tension measurements of each material employing the technique of the dynamic alveolar model are shown in Table 2. Only natural surfactant, DPL/u-PG, and URI analog had minimal surface tensions in the normal range (i.e., below 10 dynes $/ \mathrm{cm}$ ). Furthermore, it is evident that the materials containing unsaturated phospholipids possessed good surface activity, each with stability indices exceeding 1.0, whereas those containing only saturated phospholipids had significantly lower surface activity with stability indices less than 0.4 .

Wilhelmy balance studies showed that each phospholipid mixture (except URI analog) reached a minimal surface tension under 10 dynes/cm when the concentration of phospholipid was between $0.24 \mu \mathrm{moles} / \mathrm{cm}^{2}$ and $0.48 \mu \mathrm{moles} / \mathrm{cm}^{2}$. The URI analog showed the highest surface activity of the seven phospholipid mixtures on the Wilhelmy balance at a phospholipid concentration of 0.01 $\mu$ moles $/ \mathrm{cm}^{2}$. Natural surfactant reached a minimal surface tension at a phospholipid concentration of $0.0015 \mu \mathrm{moles} / \mathrm{cm}^{2}$.

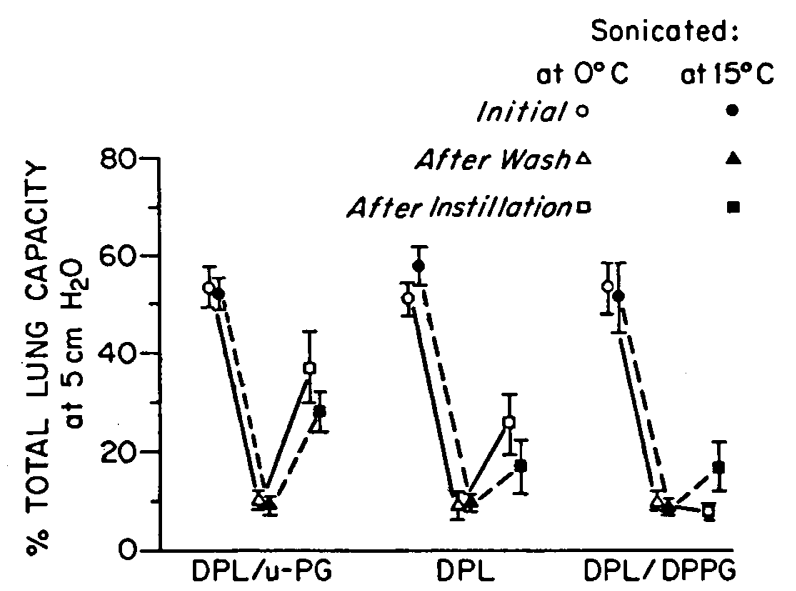

Fig. 3. A comparison of the percent of total lung capacity at $5 \mathrm{~cm} \mathrm{H}_{2} \mathrm{O}$ for control lungs, lungs washed with $200 \mathrm{ml}$ saline, and washed lungs that were treated with three different phospholipid mixtures sonicated at $0^{\circ} \mathrm{C}$ and those mixtures sonicated at $15^{\circ} \mathrm{C}$.

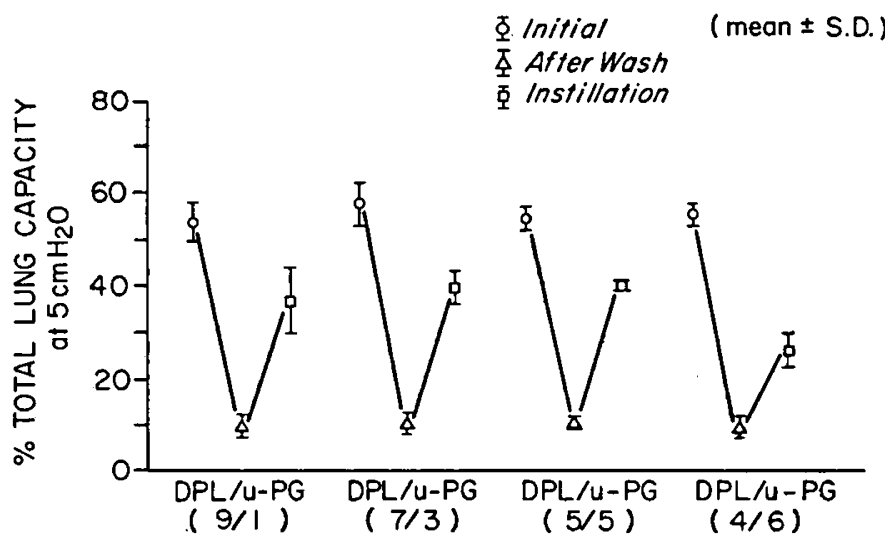

Fig. 4. A comparison of the percent of total lung capacity at $5 \mathrm{~cm} \mathrm{H}_{2} \mathrm{O}$ for control lungs, lungs washed with saline, and washed lungs that were treated with four different ratio mixtures DPL with unsaturated phosphatidyl glycerol (u-PG). In each case, $n=5$. Concentration of phospholipid $=5 \mathrm{mg} / \mathrm{ml}$.
Because the concentration of PG in lung washings is approximately $6-12 \%$ of the total phospholipids $(9,17,18)$, it initially seemed reasonable for us to use a molar mixture of 9 parts DPL to 1 part PG. Additional studies were performed, however, using three other molar mixtures of DPL/u-PG as follows: $7 / 3,5 / 5$, and 4/6. The total PL concentration of each mixture was $5 \mathrm{mg} / \mathrm{ml}$ and the temperature during sonication was $0^{\circ} \mathrm{C}$. As can be seen in Figure 4, molar mixtures of $9 / 1,7 / 3$, and $5 / 5$ seemed to produce similar good results; only the mixture of $4 / 6$ was less effective. Similar favorable results of the three molar mixtures were obtained when the suspensions were studied using the dynamic alveolar model as shown in Table 3.

\section{DISCUSSION}

It would appear that DPL is the major phospholipid of lung surfactant producing lung stability. However, when used by itself and placed directly into the lungs, it is not nearly as effective as natural surfactant. This study has demonstrated that DPL is more effective when used in combination with unsaturated phosphatidyl glycerol (u-PG). The significance of $\mathrm{u}-\mathrm{PG}$ in lung stability is not clear at this time, but it may play a role in the stabilization of the surfactant lipoprotein complex (7) due to its physical properties $(11,15)$.

During sonication, the temperature of the suspension immediately surrounding the sonicating probe escalated to values exceeding $100^{\circ} \mathrm{C}$. This required that the sonicating vessel be maintained in a cold water bath $\left(0^{\circ} \mathrm{C}\right)$. Desiring, however, to approximate as closely as possible the techniques of Ivey et al. (13), we also sonicated selected mixtures in a bath at $15^{\circ} \mathrm{C}$. Our results are comparable with those of Ivey et al. (13) in that DPL/DPPG improves lung stability to a slight degree; however, the improvement observed by us using the rat lung model occurred only when the suspension was sonicated at $15^{\circ}$ and not at $0^{\circ} \mathrm{C}$. Thorough sonication probably is important especially if done at $0^{\circ} \mathrm{C}$. Our results would indicate that the temperature of sonication is important. In our previous study (12), the DPL was only sonicated for 1-2 min (and not until the suspension appeared opalescent) before it was instilled into the lungs. Under those circumstances, the \% TLC at $5 \mathrm{~cm} \mathrm{H}_{2} \mathrm{O}$ was 16.8 compared with our present results of 25.8 following thorough sonication.

The chemical composition of pulmonary surfactant has evolved in such a way that its constituents are both able to be rapidly adsorbed to the alveolar surface and once adsorbed to reduce the surface tension to the low values necessary for alveolar stability (14). Each of the phospholipid mixtures used had the ability to lower the surface tension to under 10 dynes/cm utilizing the dynamic alveolar model if adsorbed to the surface of the bubble by using lipid mixtures dissolved in chloroform rather than sus-

Table 3. Surface tension measurements in a dynamic alveolar model of various mixtures of $D P L / u-P G(\text { dynes } / \mathrm{cm})^{1}$

\begin{tabular}{lcccccc}
\hline & \multicolumn{6}{c}{ DPL/U-PG } \\
\cline { 2 - 7 } & $(10 / 0)$ & $(9 / 1)$ & $(7 / 3)$ & $(5 / 5)$ & $(4 / 6)$ & $(0 / 10)$ \\
\hline$\gamma$ min. & 59 & 5 & 6 & 24 & 62 & 55 \\
$\gamma$ max. & 72 & 65 & 63 & 72 & 72 & 69 \\
SI & 0.2 & 1.7 & 1.7 & 1.0 & 0.1 & 0.2 \\
\hline
\end{tabular}

' Concentration of phospholipid $=5 \mathrm{mg} / \mathrm{ml}$.

Table 2. Surface tension measurements in a dynamic alveolar model of surface active materials sonicated at $0^{\circ} \mathrm{C}($ dynes $/ \mathrm{cm})$

\begin{tabular}{lcccccccc}
\hline & $\begin{array}{c}\text { Natural } \\
\text { surfactant }\end{array}$ & DPL/u-PG & DPL/u-PI & DPL' & DPL/u-PS & DPL/u-lecithin & DPL/DPPG & URI analog \\
\hline$\gamma \min$ & 0 & $5(20)$ & 18 & $69(62)$ & 20 & 19 & $66(46)$ & 2 \\
$\gamma \max$ & 38 & $65(59)$ & 68 & $79(78)$ & 72 & 71 & $77(66)$ & 50 \\
SI & 2.0 & $1.7(1.0)$ & 1.2 & $0.1(0.2)$ & 1.1 & 1.2 & $0.2(0.4)$ & 1.9 \\
\hline
\end{tabular}

\footnotetext{
${ }^{1}$ Numbers in ( ) equals values of material sonicated at $15^{\circ} \mathrm{C}$.
} 
pended in saline. Therefore, our surface tension measurements suggest that the unsaturated phospholipids possess an additional property assisting in adsorption of the surfactant to the alveolar surface.

There is a correlation between the extent of film expansion and surface activity in phospholipid monolayers (23). It has been demonstrated that pronounced shifts in surface tension properties of a given class of phosphatides are brought about by variations in the apolar moiety $(21,23)$. Salem $(19)$ has shown that the total dispersion energy between two linear hydrocarbon lipid chains, opposed and parallel, a distance D apart, each built out of $\mathrm{N}$ subunits is found to be Wdisp. $=\mathrm{K} N / \mathrm{D}^{5}$. Hence, the total attraction energy is proportional to the number of units in each of the interacting molecules, and also proportional to the inverse fifth power of the intermolecular distance. One may, therefore, expect rather large forces between long chains, and also a very sensitive change of the forces with distance even when these molecules are in close contact. The unsaturated phosphoglycerides used in these studies generally contain an unsaturated fatty acid chain in position $\beta$. There will be steric hindrance between unsaturated chains belonging to neighboring phosphoglycerides, thus, increasing intermolecular distance. As a result, the value of $D^{5}$ is much longer between two adjacent molecules; hence a smaller Van der Waals attraction and decreased cohesion. Finally, because surface tension can be considered to represent the work required to expand a unit area of surface (dynes $/ \mathrm{cm}=\mathrm{ergs} / \mathrm{cm}^{2}$ ), then the decreased cohesion results in reduced surface tension through a decrease in the forces which must be overcome to expand the surface.

Our studies of various molar mixtures of DPL/u-PG showed that the ability to restore PV characteristics was greatly reduced when the concentration of $\mathrm{u}-\mathrm{PG}$ in the mixture exceeded $50 \%$ of the phospholipid present. In light of the latter expression for dispersion energies between parallel lipid chain, one possible explanation for these results is that too much unsaturation induces too great a spreading and spacing between molecules, thus, reducing intermolecular attraction energy below that necessary for film stability.

\section{CONCLUSION}

The surfactant depleted adult rat lung model was used to determine the ability of certain phospholipids, either singly or in combination, to restore the lung PV characteristics to normal. Although six of the seven suspensions used possessed some ability to restore the PV characteristics toward normal, none was as effective as natural surfactant. Of the seven phospholipid mixtures, DPL/u-PG produced the most improvement in lung stability.

\section{REFERENCES AND NOTES}

1. Adams, F. H., and Enhorning, G.: Surface properties of lung extracts. I. A dynamic alveolar model. Acta Physiol. Scand., 68: 23 (1966).
2. Adams, F. H., Towers, B., Osher, B. A., Ikegami, M., Fujiwara, T., and Nozaki, M.: Effects of tracheal instillation of natural surfactant in premature lambs: I Clinical and autopsy findings. Pediatr. Res., 12: 841 (1978).

3. Chu, J., Clements, J. A., Cotton, F. K., Klaus, M. H., Sweet, A. Y., and Tooley W. H.: Neonatal pulmonary ischemia. Pediatrics, 40: 709 (1967).

4. Clements, J. A.: Surface tension in the lung. Scientific Am., 207: 120 (1962).

5. Enhorning, G., and Robertson, B.: Lung expansion in the premature rabbit fetus after tracheal deposition of surfactant. Pediatrics, 50: 58 (1972).

6. Fujiwara, T., Adams, F. H., Sipos, S., and El-Salway, A.: "Alveolar" and whole lung phospholipids of the developing fetal lamb lung. Amer. J. Physiol., 215: 375 (1968).

7. Godinez, I. R., Sanders, L. R., Longmore, J. W.: Phosphatidyl glycerol in rat lung. I. Identification as a metabolically active phospholipid in isolated perfused lung. Biochemistry, 14: 830 (1975).

8. Gribetz, J., Frank, N. R., and Avery, M. E.; Static volume-pressure relations of excised lungs of infants with hyaline membrane disease, newborn and stillborn infants. J. Clin. Invest., 38: 2168 (1959).

9. Hallman, M., Feldman, H. B., Kirkpatrick, E., and Gluck, L.: Absence of phosphatidyl glycerol in respiratory distress syndrome in the newborn. Pediat. Res., 11: 714 (1977).

10. Hallman, M., Kulovich, M., Kirkpatrick, E., Sugarman, G. R., and Gluck, L.: Phosphatidyl inositol and phosphatidyl glycerol in amniotic fluid: Indices of lung maturity. Amer. J. Obstet Gynecol., 125: 613 (1976).

11. Henderson, T. O., Glonek, T., Myers, T. C.: Phosphorus-31 nuclear magnetic resonance spectroscopy of phospholipids. Biochemistry, 13: 623 (1974).

12. Ikegami, M., Hesterberg, T., Nozaki, M., and Adams, F. H.: Restoration of lung pressure-volume characteristics with surfactant. Comparison of nebulization versus instillation and natural versus synthetic surfactant. Pediatr. Res., 11: 178 (1977).

13. Ivey, H., Roth, R., and Kattwinkel, M.: Nebulization of sonicated phospholipids for treatment of respiratory distress syndrome of infancy. Pediat. Res., 11: 573 (1977).

14. King, R. J., Clements, J. A.: Surface active materials from dog lung. II Composition and physiological correlations. Amer. J. Physiol., 223: 715 (1972).

15. Michaelson, D. M., Horwitz, A. F., and Klein, M. P.: Transbilayer asymmetry and surface homogeneity of mixed phospholipids in cosonicated vesicles. Biochemistry, 12: 2637 (1973).

16. Nozaki, M.: Pressure-volume relationships of model alveolus. Tohoku J. Exptl. Med., 101: 271 (1970).

17. Pfleger, R. C., Thomas, H. G.: Beagle dog pulmonary surfactant lipids. Arch Intern. Med., 127: 863 (1971).

18. Rooney, S. A., Page-Roberts, B. A., and Motoyama, E. K.: Role of lamellar inclusions in surfactant production studies on phospholipid composition and biosynthesis in rat and rabbit lung subcellular fractions. J. Lipid Res., 16: 418 (1975).

19. Salem, L.: The role of long-range forces in the cohesion of lipoproteins. Can. J. Biochem. Physiol., 40: 1287 (1962).

20. Sanders, R. L., Longmore, J. W.: Phosphatidyl glycerol in rat lung. II. Comparison of occurrance, composition, and metabolism in surfactant and residual lung fractions. Biochemistry, 14: 835 (1975).

21. Shah, D. O.: The biology of surfaces. In: C. E., Villee, D. B., Villee, J. Zuckerman: Respiratory Distress Syndrome. p. 47 (Academic press, 1973).

22. Shannon, D. C., Kazemi, H., Merril, E. W., Smith, K. A., and Wong, P. S. L.: Restoration of volume-pressure curves with lecithin fog. J. Appl. Physiol., 28: $470(1970)$

23. Van Deenen, L. L. M., Houtsmuller, U. M. T., de Haas, G. H., and Mulder, E.: Monomolecular layers of synthetic phosphatides. J. Pharm. Pharmacol., 14: 429 (1962).

24. The authors thank Dr. Masao Abe and Dr. Alex Sevanian for their help and advice.

25. This research was supported by funds from the United States Public Health Service and the National Cystic Fibrosis Research Foundation.

26. Received for publication April 7, 1978.

27. Accepted for publication July 19, 1978. 